\title{
(Des)caminhos da Educação Pública no Brasil
}

A ETD nos apresenta neste número o dossiê "Educação e Classes Sociais" um tema bastante oportuno em função dos acontecimentos recentes envolvendo a agenda educacional brasileira. Trata-se de uma agenda que se inscreve num contexto de ajuste fiscal e que tem impulsionado os gestores públicos a adotarem medidas de caráter gerencial que aprofundam e aceleram o processo de desmonte da educação pública em nosso país.

Há duas décadas a Educação Pública no Brasil está sob risco. As inúmeras reformas que ocorreram, a partir de 1990, nas políticas públicas educacionais no âmbito nacional coadunaram com as orientações advindas dos organismos internacionais (Banco Mundial e Fundo Monetário Internacional) por meio da "Declaração Mundial sobre Educação para Todos". O objetivo era o de promover a universalização da educação e melhorar a qualidade do ensino a partir de critérios gerenciais.

O fundamento ideológico do discurso teve como objetivo combater o "Estado-SocialBurocrático" para consolidar o Estado-Social-Liberal reconfigurado sob a denominação “Nova Gestão Pública”.

Nessa Reforma do Estado (Nova Gestão Pública), a organização e o processo do trabalho configura-se no modelo empresarial que tem no seu bojo a eficiência e a eficácia, o discurso da qualidade para fins quantitativos, a racionalização econômica e instrumental. Esses critérios foram consubstanciados nas políticas públicas educacionais, a saber: a) Leis de Diretrizes de Base da Educação Nacional - LDBN (9.394/1996), b) avaliação externa (SAEB), c) FUNDEF (Financiamento para o Ensino Fundamental), d) redefinição curricular (competências e habilidades) baseada na formação utilitarista dos educandos para o mercado de trabalho.

Essas primeiras reformas tiveram como finalidade atender as demandas do capital no processo da reestruturação produtiva, 
no sentido de formar uma força de trabalho mais flexível e adaptada aos novos processos produtivos. Por essa razão, a educação pública brasileira perde, em detrimento dessa formação de cunho utilitário, o sentido de formar alunos críticos e reflexivos segundo uma concepção de formação humanística prevista na Constituição Brasileira de 1988.

A partir dos anos 2000 assistimos, no campo das políticas educacionais, o aprofundamento de esquemas gerenciais centrados em metas, resultados e responsabilização das escolas e de seus profissionais. A responsabilização se fará pela disseminação de esquemas de vigilância e punição que compreendem o financiamento e a bonificação atrelados às avaliações externas. São estratégias que promovem uma maior responsabilização dos profissionais da educação combinada com a desresponsabilização do Estado. São práticas concebidas atualmente com apoio do setor empresarial através de suas fundações, segmento este que vem aprofundando sua participação nas tomadas de decisões em termos de políticas públicas educacionais desde o surgimento do movimento "Todos pela Educação" em 2006.

Com a aprovação do Plano Nacional da Educação, lei n 13.005/2014 de 25 de junho de 2014, abriu-se e aprofundou-se de forma legalizada o campo fragilizado e desprotegido da educação pública para os empresários da educação. Vale destacar o que está disposto em seu $\S 4^{\circ}$ do Artigo $5^{\circ}$, que considera, para efeito de cumprimento da meta 20 referente aos $10 \%$ do PIB para a Educação, recursos que incluem isenções fiscais e subsídios ao FIES (Fundo de Financiamento Estudantil). Esse artifício deverá dificultar ainda mais a ampliação dos recursos necessários à melhoria da qualidade da educação pública, uma vez que também se desdobrou nas propostas de muitos Planos Estaduais e Municipais de Educação.

A lei do PNE exigiu, nos artigos $7^{\circ}$ e $11^{\circ}$, que os municípios e os Estado elaborassem em um ano seus próprios planos de educação, cujo prazo foi fixado para agosto de 2015 . O artigo $8^{\circ}$ fixa a colaboração e o artigo $11^{\circ}$ destaca a importância dos indicadores de resultados e a disseminação de informações.

A aprovação desses planos, com prazo fixado em Lei, promoveu a aceleração e o aligeiramento do processo de elaboração. Ao "disciplinar a democracia", limitou-se o processo de debate democrático e a representação popular nos fóruns constituídos para essa tarefa. O que se verificou também é que em função do prazo fixado, muitos municípios recorreram de forma pragmática aos serviços de consultorias privadas para assessorar o \begin{tabular}{|c|c|c|c|c|c|c|} 
(C) ETD - Educ. temat. digit. & Campinas, SP & v.17 & n. 3 & p.463-470 & set./dez.2015 & ISSN 1676-2592
\end{tabular} 
processo e a elaboração do texto final. As primeiras análises dos Planos elaborados, por exemplo, no âmbito da Região Metropolitana de Campinas, tem demonstrado que os documentos elaborados e apresentados estão reproduzindo as metas fixadas no PNE, sem um devido diagnóstico da situação da educação nesses municípios. Até a conclusão desse editorial, 11 estados brasileiros não haviam sancionado seus respectivos planos.

Durante o processo de elaboração dos Planos Estaduais e Municipais de Educação o debate de gênero roubou a cena. As ondas conservadoras impulsionadas pela bancada evangélica nos espaços de debate deturparam a relevância do tema, inclusive com a ocorrência de agressões físicas durante as audiências públicas. Foi o que aconteceu no município de Campinas quando da agressão a uma professora dentro da Câmara Municipal, quando fazia a defesa de seu posicionamento sobre urgente necessidade de enfrentarmos, em todos os níveis de ensino, o tema da orientação sexual e as questões de gênero no cotidiano escolar, bem como na sociedade brasileira.

Neste ano de 2015, vivemos em tempos difíceis com os cortes previstos no orçamento da pasta da educação anunciados pelo Governo Federal no início do ano, podendo chegar a 9,42 bilhões de reais. Com as medidas de ajuste fiscal, os primeiros setores que sofreram foram os das áreas sociais, como a previdência social, a saúde e a educação. Essa agenda resultou em cortes também em nível dos Estados e municípios, resultando em greves e mobilizações dos profissionais da educação em todo Brasil.

No Estado do Paraná, os docentes e funcionários anunciaram greve, após o conjunto de medidas adotadas pelo Governador Beto Richa (PSDB) em relação às aposentadorias dos servidores públicos. Essa greve ficou marcada em todo Brasil, pela forte repressão policial e pela ausência de negociação. A forma truculenta da ação da policial, resultaram em agressão física a professores e alunos da rede pública daquele Estado.

No mesmo período, os professores, no Estado de São Paulo, enfrentaram 92 dias de greve, considerada a maior da história da APEOESP (Sindicato dos Professores do Ensino Oficial de São Paulo). O movimento foi solapado pelo descaso do Governador Geraldo Alckmin (PSDB) e pela grande mídia. Ao ignorar a existência e sua legitimidade o governo não sentou à mesa para negociar. O falso discurso, que dava uma previsão de aumento para categoria no dia primeiro de julho, resultou no encerramento da greve sem nenhum aumento e, na data prometida pela Secretaria da Educação, o reajuste foi zero. 
Nesse período, chamou a atenção o projeto lançado pelo Governo de Goiás que pretende terceirizar a gestões de escolas públicas da rede estadual por meio de organizações sociais (OSs). O decreto foi assinado pelo governador Marconi Perillo (PSDB) no último dia 14 de outubro. A Secretaria de Estado da Educação, Cultura e Esporte (Seduce) irá selecionar ainda neste ano de 2015 as entidades interessadas. Trata-se de um projeto inédito que poderá produzir efeitos nocivos à carreira docente gerando maior instabilidade e precarização. $\mathrm{O}$ sindicato dos professores vem chamando a atenção para o caráter anti-sindical da medida e para a falta de transparência do processo, principalmente pela falta de clareza sobre o quanto os professores contratados pelas OSs irão ganhar e se a lei do piso nacional será cumprida.

As Organizações Sociais devem aprofundar o projeto pedagógico de viés empresarial centrado em resultados, controle e responsabilização docente. Vale ressaltar que essa terceirização concretiza-se para atender a educação como mercadoria e não como um bem público e social. O governo de Goiás é emblemático, uma vez que também vem militarizando escolas, num total de oito estabelecimentos, numa clara intenção de combater a "extrema esquerda", conforme transcrição de vídeo de um pronunciamento do governador Marconi Perillo gravado no último dia 17 de novembro na Bahia.

O Pará, na mesma direção que Goiás, também quer adotar o esquema de escolas Charters. O governo, sob protestos dos trabalhadores da educação do estado, já possui projeto para transferir para as OSs 50 escolas de ensino médio que serão construídas e geridas por "parceiros". O projeto foi assinado em acordo com o IFC (Corporação Financeira Banco Mundial). Não bastasse isso, o Governador Simão Jatene assinou contrato de R\$ 11 milhões com empresas privadas para o treinamento e reforço escolar aos alunos da rede estadual, com a intenção de melhorar os resultados no IDEB. O modelo de PPP (Parcerias PúblicoProvadas) na Educação está em discussão em diversas unidades da federação com destaque para o Paraná, Rio Grande do Sul e Espírito Santo, além dos que já destacamos.

No dia 27 de setembro, o então Secretário da Educação do Estado de São Paulo, Professor Dr. Herman Voorwald, faz o pronunciamento sobre a reorganização escolar, na televisão, que, segundo este é a melhor forma de se comunicar com os profissionais da rede. A proposta de reorganização apresentada que visava, segundo o secretário, à qualidade de ensino, promovendo o segmento de ciclo único, melhoraria o rendimento dos alunos em $10 \%$. 
A posteriori foi realizada uma videoconferência, no 29 de setembro pelo site oficial da Secretaria da Educação do Estado de São Paulo para informar os detalhes do projeto, que baseou-se em três variáveis, sendo essas: a) diminuição da queda da taxa de natalidade (redução de dois milhões de alunos na rede estadual), b) municipalização dos anos iniciais do ensino fundamental na década de 1990 e, c) melhoria do poder aquisitivo das famílias e o ingresso nas escolas particulares.

A divulgação do projeto impulsionou uma grande onda de protestos em todo Estado durante o mês de outubro por todo estado de São Paulo, demonstrando a insatisfação dos estudantes em não serem ouvidos pela Secretaria da Educação sobre esse processo da reorganização, envolvendo também o anúncio do fechamento de 94 escolas e a transferência de milhares de alunos de suas escolas de origem.

No dia 10 de novembro, os estudantes da Escola Estadual Fernão Dias Paes (Pinheiros-SP) ocuparam este estabelecimento para chamar atenção da sociedade para a impropriedade da aplicação desse projeto na rede. As mobilizações e as ocupações que se desdobraram a partir desta primeira, denunciaram a ausência do diálogo e a falta de um estudo mais apurado sobre as implicações da aplicação da medida. A ocupação da escola em questão foi marcada pela pressão da Polícia Militar em torno da escola, desde o controle de entrada e saída dos estudantes, corte de água e luz, a não entrada de alimentos e a forma constrangedora pela ação da Secretaria de Segurança Pública em filmá-los a todo tempo.

A maneira como a Secretaria da Educação e da Segurança Pública tratou essa mobilização foi o combustível da revolta na sociedade e gerou muitas outras ocupações que se espalharam por todo Estado. No final de novembro o número de escolas ocupadas já ultrapassava 200 unidades.

As entidades do magistério, as universidades públicas estaduais (UNICAMP, USP e UNESP) e federais (UNIFESP, UNIABC e UFSCAR) do estado e entidades como a Associação Nacional de Pesquisa em Financiamento da Educação (FINEDUCA); Associação Nacional de Política e Administração da Educação (ANPAE); ANPAE - São Paulo; Associação Nacional pela Formação dos Profissionais da Educação (ANFOPE); Centro de Estudos Educação e Sociedade (CEDES); Grupo de Trabalho "Estado e Política Educacional" - GT 5 da Associação Nacional de Pesquisa e Pós- 
Graduação em Educação (ANPED) publicaram moções em apoio às mobilizações do estudantes e contrárias a reorganização proposta pelo governo.

A moção da Faculdade de Educação da UNICAMP, por exemplo, questiona os dois argumentos centrais da proposta da Secretaria da Educação. Como segue:

De que escolas com apenas um segmento têm melhores desempenhos nas avaliações do Saresp e Prova Brasil embora sem uma demonstração científica que comprove tal relação, uma vez que existem, também, escolas de dois ou mais segmentos com bom desempenho no IDESP que obtiveram bons índices e escolas de um segmento que não foram tão bem de acordo com os critérios avaliativos da Secretaria da Educação. No que concerne as escolas a serem fechadas a moção questiona que das escolas 94 escolas que estão sendo fechadas, pelo menos 30, tiveram em algum ciclo nota superior à média do Indice (IDESP) que avalia as escolas. Existem 15 escolas que estavam indicadas para serem fechadas que são de segmento único. em idade escolar no Estado de São Paulo. Segundo a Secretaria Estadual de Educação, entre os anos de 1998 e 2015, a rede estadual de ensino teria perdido cerca de 2 milhões de alunos. Com isso, o governo Geraldo Alckmin justifica, em suas próprias palavras, que é preciso "um novo modelo de escola que se adeque à queda da taxa de natalidade e à redução expressiva da população em idade escolar". A moção da Faculdade questiona se não seria o momento oportuno para melhorarmos de fato a qualidade do ensino em nosso estado com a redução do número de alunos por sala, ou ainda, reduzir a jornada de trabalho dos professores no sentido de reservar mais tempo para o preparo e planejamento do trabalho.

No conjunto, essas moções questionam o projeto do governo pelo seu caráter gerencial ocultado na sua proposição tais como: a) o enxugamento da secretaria da educação com a redução do quadro docente de forma assemelhada ao processo de reorganização ocorrido nos anos 1990 em São Paulo quando foram fechadas 155 escolas e demitidos 20 mil professores; b) a preparação da rede estadual para um segundo movimento forte de municipalização pela transferência do ensino fundamental para os municípios, que vem ocorrendo desde a promulgação da LDB em 1996 e do surgimento do FUNDEF. Essa 
intenção está explicitada na Meta 21 da Proposta de Plano Estadual da Educação que o Governo enviou para a Assembleia Legislativa do Estado de São Paulo (PL 1083/2015) e; c) a preparação da rede para um movimento de privatização do Ensino Médio, tal como já vem ocorrendo em Goiás, Pará e em Pernambuco. Isso ocorrerá no Ensino Médio, tanto nas escolas em tempo integral como também na proposta de flexibilização curricular. Esse movimento está previsto nas metas 6 e 22 do PL 1083.

O projeto de reorganização integra o texto do Plano Estadual de Educação que o governo apresentou com metas para serem atingidas até 2025. Isso nos leva e crer que os números apresentados pela secretaria estadual de educação, envolvendo o fechamento de 92 escolas e de 754 escolas reorganizadas, podem ser ainda maiores, uma vez que o Plano é para 10 anos.

O movimento de ocupação das escolas que ocorre em São Paulo, contrário ao plano de reorganização da rede estadual, é um movimento vitorioso e, por essa razão, vem persistindo. A suspensão da reorganização com a revogação do Decreto 61672 /2015, no último dia 05 de dezembro, destaca a força desse movimento. No entanto, há uma compreensão geral de que este movimento precisa avançar agora para um questionamento mais profundo sobre os rumos da educação pública no Estado. É preciso não apenas enfrentar a reorganização em si no que concerne a sua face gerencial e privatizante, mas sobretudo destacar os caminhos alternativos que os estudantes têm apresentado a partir do modo de organização dessas ocupações e das atividades desenvolvidas por eles nas escolas. Essa atividade tem demonstrado que os jovens querem uma escola mais participativa, democrática e, até mesmo, autogerida.

Através das ocupações os estudantes indicam que é preciso uma nova concepção de currículo que dialogue com suas experiências, expectativas e necessidades reais. Querem apropriar-se da ciência, mas com consciência. Esse nos parece um desejo manifesto por uma educação muito distante das apostilas do "São Paulo faz Escola" e do embotamento da pedagogia voltada para os testes promovidos através do Saresp.

O movimento e a organização estudantil colocam, portanto, em xeque o modelo gerencial da Secretaria e do Governo Estadual centrado em metas, resultados e estreitamento curricular como referência de qualidade. Os jovens querem uma outra qualidade mais 
substantiva que os incluam, juntamente com os professores, pais e a comunidade, como sujeitos.

Consideramos que essas mobilizações apontam muitos caminhos para a educação em nosso país.

\author{
Andressa de Sousa Rodrigues Mesko ${ }^{1}$ \\ Evaldo Piolli ${ }^{2}$
}

Como citar este artigo:

MESKO, Andressa de Sousa Rodrigues; PIOLLI, Evaldo. Editorial. ETD - Educação Temática Digital, Campinas, SP, v. 17, n. 3, dez. 2015. ISSN 1676-2592. Disponível em:

<http://periodicos.sbu.unicamp.br/ojs/index.php/etd/article/view/8642329>. Acesso em: 16 dez. 2015.

\footnotetext{
${ }^{1}$ Professora da Educação Básica do Estado de São Paulo. Mestranda no PPGE da Faculdade de Educação da Universidade Estadual de Campinas (UNICAMP) e Membro do Coletivo Quinze de Outubro. E-mail: andressamesko@yahoo.com.br

${ }^{2}$ Professor da Universidade Estadual de Campinas (UNICAMP), Faculdade de Educação, Campinas, SP Brasil. E-mail: epiolli@unicamp.br
} 